\title{
Nanostructures in Ti processed by severe plastic deformation
}

\author{
Y.T. Zhu and J.Y. Huang \\ Materials Science and Technology Division, MS G755, Los Alamos National Laboratory, \\ Los Alamos, New Mexico 87545 \\ J. Gubicza and T. Ungár \\ Department of General Physics, Eötvös University, Budapest, P.O. Box 32, H-1518, Hungary \\ Y.M. Wang and E. Ma \\ Department of Materials Science and Engineering, The John Hopkins University, \\ Baltimore, Maryland 21218 \\ R.Z. Valiev \\ Institute of Physics of Advanced Materials, Ufa State Aviation Technical University, \\ Ufa 450000, K. Marksa 12, Russia
}

(Received 12 March 2003; accepted 23 May 2003)

\begin{abstract}
Metals and alloys processed by severe plastic deformation (SPD) can demonstrate superior mechanical properties, which are rendered by their unique defect structures. In this investigation, transmission electron microscopy and x-ray analysis were used to systematically study the defect structures, including grain and subgrain structures, dislocation cells, dislocation distributions, grain boundaries, and the hierarchy of these structural features, in nanostructured Ti produced by a two-step SPD procedure-warm equal channel angular pressing followed by cold rolling. The effects of these defect structures on the mechanical behaviors of nanostructured Ti are discussed.
\end{abstract}

\section{INTRODUCTION}

Nanostructured materials have superior mechanical properties such as high strength ${ }^{1}$ and low-temperature or high-strain-rate superplasticity. ${ }^{2-4}$ While nanostructured materials synthesized by the consolidation of nanopowders often exhibit brittle behavior, especially under tensile loading, ${ }^{1,5}$ those produced by severe plastic deformation (SPD) techniques often have both high strength and good ductility. ${ }^{6-10}$ SPD techniques refine grains by introducing large plastic strains into a coarsegrained material, typically a metal or alloy. ${ }^{11}$ Metallic materials usually exhibit higher strength but lower ductility after being plastically deformed by conventional forming methods such as rolling, drawing, or extrusion. $^{12,13}$ This trend is true at least for metals deformed by a low to medium plastic strain. It was also reported that once a metal is deformed beyond a certain plastic strain, the ductility of the metal could increase with additional plastic strain. ${ }^{10,14}$ A combination of high strength and good ductility is attractive for structural applications of nanostructured materials.

The superior mechanical properties of nanostructured materials are rendered by their unique nanostructures. The nanostructures determine the deformation mechanisms, which in turn determine the mechanical behaviors. It is not well understood why the SPD-processed nanostructured materials have high strengths while retaining good ductility. These materials are $100 \%$ dense and contamination free, which certainly contribute to their good ductility. More importantly, they have unique nanostructures that are significantly different from nanomaterials synthesized by consolidation of nanopowders. The first step toward understanding the mechanical behaviors of these materials is to systematically characterize their nanostructures. Huang et al. recently characterized the nanostructures of $\mathrm{Cu}$ produced by a SPD technique, repetitive corrugation and straightening (RCS), using transmission electron microscopy (TEM) and high-resolution TEM (HRTEM). ${ }^{15}$ They observed both equilibrium and non-equilibrium grain boundaries (GBs), subgrain structures, dislocation tangle zones (DTZs), dislocation cells (DCs), dense dislocation walls (DDWs), and various types of dislocations. However, no attempt was made to systematically characterize the hierarchy and interrelationships of these nanostructures.

Hansen and coworkers have systematically studied the evolution of microstructures in rolled face-centeredcubic (fcc) metals with medium to high stacking fault energies, such as $\mathrm{Al}$ and $\mathrm{Cu} .{ }^{16-18}$ However, nanostructures were not fully developed in these metals because the plastic strains in their studies were much lower than those introduced to nanostructured metals produced by 
SPD techniques. Horita et al., ${ }^{19}$ Oh-ishi et al., ${ }^{20}$ and Valiev et $a l .^{21}$ studied the GB structures of a few nanostructured metals and alloys produced by equal channel angular pressing (ECAP), and found the GB "wavy and faceted and in high energy non-equilibrium configurations." They did not systematically study other nanostructures.

Recently, we have developed a two-step SPD processECAP followed by cold rolling - to produce nanostructured commercially pure (CP) Ti. ${ }^{22}$ ECAP was conducted at $400-450{ }^{\circ} \mathrm{C}$ because Ti lacks sufficient ductility at lower temperatures. The warm ECAP increased the yield strength of CP-Ti by $68 \%{ }^{7}$ to $640 \mathrm{MPa}$, and the cold rolling at room temperature further increased the yield strength to over $900 \mathrm{MPa}^{9}$ while maintaining a strain to failure of $9.2 \%$ under tensile load. One of the most significant features of the stress-strain curves of nanostructured CP-Ti is the lack of strain hardening.

The objective of this paper is to systematically characterize the defect structures and their hierarchy in the CP-Ti processed by ECAP and cold rolling. The effects of defect structures on the mechanical behaviors of the CP-Ti will also be discussed.

\section{EXPERIMENTAL}

\section{A. Sample preparation}

$\mathrm{CP}$-Ti billets with an average grain size of $10 \mu \mathrm{m}$ were processed using a $90^{\circ} \mathrm{ECAP}$ die following route $\mathrm{B}_{\mathrm{C}}$ for eight passes at $400-450{ }^{\circ} \mathrm{C}$. In this ECAP route, the work-piece was rotated $90^{\circ}$ clockwise along its longitudinal axis between consecutive passes. The ECAPed Ti billets were further processed by cold rolling at room temperature to a total strain (reduction in cross-section area) of $73 \%$. Readers are referred to Ref. 22 for more details on the processing of nanostructured CP-Ti.

\section{B. Transmission electron microscopy}

The as-processed CP-Ti was characterized by TEM, which was carried out in a JEOL 3000 FEG (Tokyo, Japan) electron microscope operated at $300 \mathrm{kV}$. The point-to-point resolution was about $1.8 \AA$. TEM samples were prepared by jet electropolishing at room temperature. The electrolyte consists of $33 \%$ orthophosphoric acid and $67 \%$ water.

\section{X-ray diffraction analysis}

The microstructure was also characterized by x-ray diffraction peak profile analysis. The x-ray analysis samples material volumes that are several orders of magnitude larger than TEM, thus providing average and representative structural information that cannot be obtained by TEM. The line profile analysis was carried out on the most intense reflection peaks: $\{0002\},\{01 \overline{1} 1\},\{10 \overline{1} 2\}$, $\{0004\},\{01 \overline{1} 0\},\{11 \overline{2} 0\},\{20 \overline{2} 0\}$, and $\{02 \overline{2} 1\}$. The profiles were measured by a high-resolution double-crystal diffractometer (Nonius, FR 591, Deft, The Netherlands) using $\mathrm{Cu} \mathrm{K}_{\alpha_{1}}$ radiation. The instrumental broadening $\left[\Delta(2 \Theta)_{\text {instr }}=0.012^{\circ}\right]$ was negligible, compared to the physical peak broadening for the titanium sample $\left[\Delta(2 \Theta)_{\text {phys }}=0.4\right.$ to $\left.0.6^{\circ}\right]$. Therefore, no instrumental corrections were applied.

The crystallite size distribution and the type and density of dislocations were determined by peak profile analysis on the above eight reflections, using the recently developed multiple whole profile fitting method. ${ }^{23,24}$ In this procedure, the Fourier transforms of the experimental peak profiles are fitted by the product of the theoretical functions of size and strain Fourier transforms. The strain is assumed to be caused by dislocations. The crystallites are modeled by spheres with a lognormal size distribution, and the strain was described by the Wilkens function. ${ }^{25,26}$ The major steps of the analysis are: (i) subtract the background; (ii) determine the Fourier transform of the experimental profiles by a non-equidistant sampling Fourier transformation; (iii) normalized the experimental Fourier transforms and fit them simultaneously with the products of the theoretical size and strain Fourier transforms using the MarquardtLevenberg least squares method. ${ }^{23,24}$

The procedure is based on six fitting parameters in the case of hexagonal crystals: (i) the median $(m)$ and (ii) the variance $(\sigma)$ of the log-normal size distribution function; (iii) the dislocation density ( $\rho$ ); (iv) the dislocation arrangement parameter $* M=R_{\mathrm{e}} \sqrt{\rho}$ where $R_{\mathrm{e}}$ is the effective outer cut-off radius of dislocations; ${ }^{26}$ and (v and vi) the parameters $q_{1}$ and $q_{2}$, which describe the average dislocation contrast factors. The value of $M$ gives the strength of the dipole character of dislocations. A higher $M$ value corresponds to weaker dipole character and weaker screening of the displacement fields of dislocations. From the values of $q_{1}$ and $q_{2}$, the relative fractions of $\langle a\rangle,\langle c\rangle$, and $\langle c+a\rangle$ type dislocations were determined by a procedure described in Ref. 27. From $m$ and $\sigma$ the arithmetic mean size (diameters) of the crystallites was calculated as ${ }^{28,29}$

$$
\bar{d}=m \exp \left(0.5 \sigma^{2}\right) .
$$

\section{RESULTS}

\section{A. Nanostructures characterized by TEM}

Figure 1 shows grain structures observed from (a) the cross section and (b) the longitudinal section of a nanostructured CP-Ti billet. All TEM micrographs in this paper except Fig. 1(b) are from cross sections. Figure 1(a) shows that many grains have an irregular shape with 
sharp corners. A large fraction of GBs are wavy and not well delineated, which is typical for GBs generated by SPD. ${ }^{19-21}$ The linear intercept grain size measured from the cross section is $265 \mathrm{~nm}$, which is an average of over 150 grains. The grain size was measured using the Hilliard single-circle intercept procedure (ASTM Standard E112-96). Figure 1(b) shows that some grains are elongated while other grains are equiaxed. This is in sharp contrast to nanostructured $\mathrm{Ti}$ produced by ECAP plus cold rolling to a strain less than $55 \%$, in which most

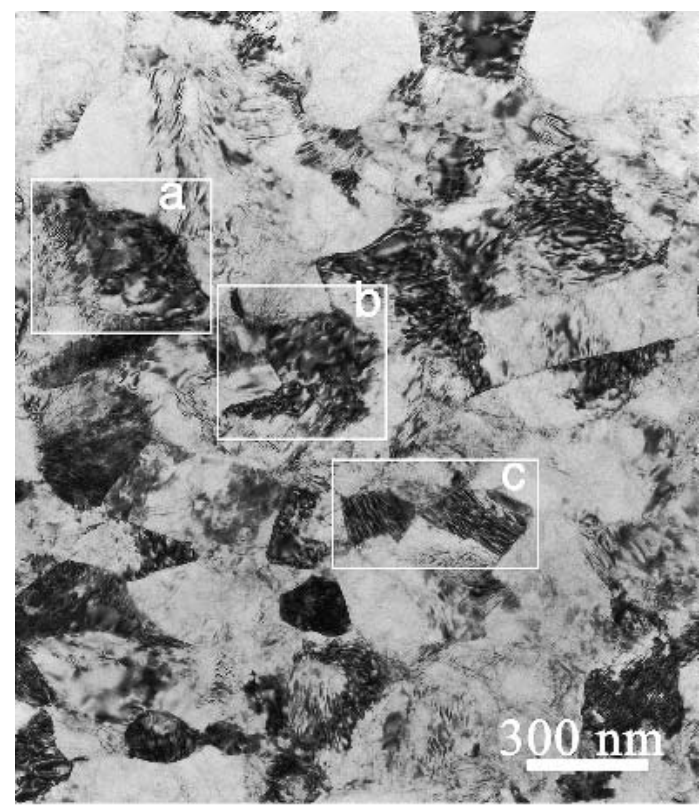

(a)

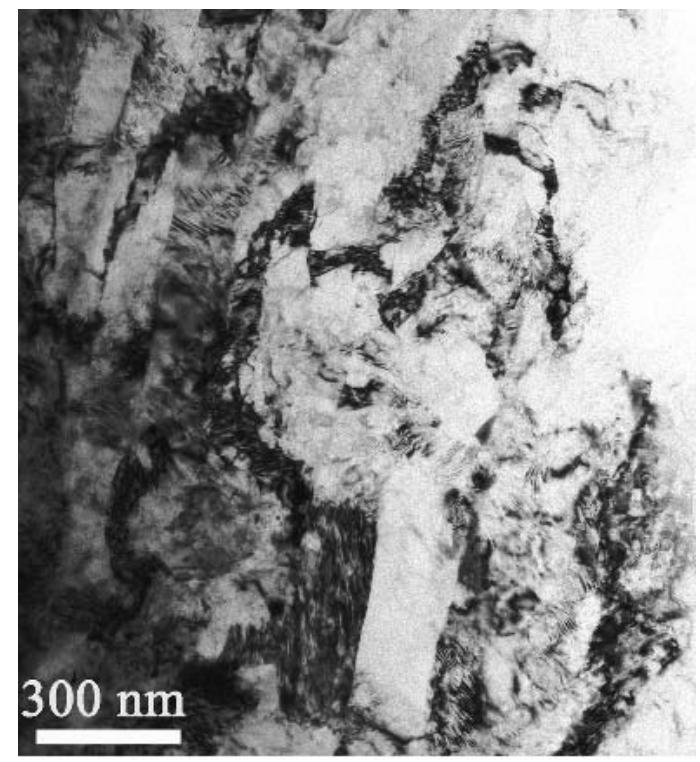

(b)

FIG. 1. Grain structures observed from the (a) cross section and (b) longitudinal section of a nanostructured CP-Ti billet produced by warm ECAP plus cold rolling. grains are filamentary in the longitudinal section. ${ }^{22}$ The equiaxed grains were formed by the fragmentation of elongated grains.

The heterogeneous contrasts shown inside grains in Fig. 1 were caused by defects such as dislocations. Such defects can be viewed in detail at higher magnifications. Figure 2 is the enlargement of area a in Fig. 1(a). It can be seen that the dislocation density is higher near the GB (marked as B) than in the interior of the grain and dislocation cells formed inside the grain. Figure 3 shows a grain (marked as H), from area b of Fig. 1(a). It has a relatively homogeneous dislocation distribution. Another grain marked as $\mathrm{F}$ has a low angle $\mathrm{GB}$ with grain $\mathrm{H}$, judging from their similar contrast. An often-observed feature is the banded-contrast image (BCI), as shown in Fig. 4(a), which is from area $\mathrm{c}$ in Fig. 1(a). As shown, parallel, long black and gray bands formed in two grains (marked by white arrows). We believe that such images were formed from the strain fields of high-density dislocations. When such dislocations, approximately parallel to each other and possibly with the same Burgers vector, are oriented to a certain angle to the electron beam, their strain fields, or the interaction of their strain fields, will generate the BCI. This argument is supported by Fig. 4(b), which shows both dislocations and a partially formed BCI. As shown, some dislocations are aligned along a line between two black arrows, and the BCIs are formed on both sides of the line.

Figure 5 shows a grain (marked as A) with different types of GB segments. On the upper and left sides (marked by black triangles) are sharp, high-angle GBs, while on the lower and right sides the GBs are wavy, not well delineated, and most likely low-angle. The exact locations of some GB sections on the lower and right sides (marked by white dots) are even hard to determine because boundaries with neighboring grains have not been well developed. The misorientation across

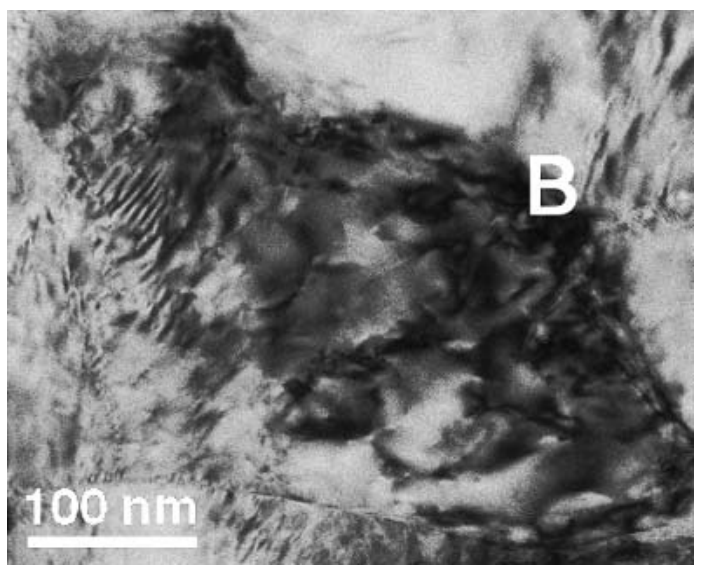

FIG. 2. Higher dislocation density near the grain boundary in a grain from area a in Fig. 1(a). 
these not-well-developed boundaries could be only a few degrees. Although this grain is relatively large, it contains only dislocation cells, not the intermediate subgrains.

Figure 6 shows a grain that contains both a DTZ and DCs. The DCs could be formed from the DTZ through a recovery process, i.e., the interaction, annihilation, and rearrangement of dislocations. Figure 7 shows a grain in which dislocations lined up across the grain along three paths as marked by three pairs of arrows. It is not clear what made the dislocations arrange themselves in such a manner. This grain could show BCI if it is oriented with a certain angle with the electron beam. DCs exist at the lower end of the grain. Another grain marked as $\mathrm{F}$ is

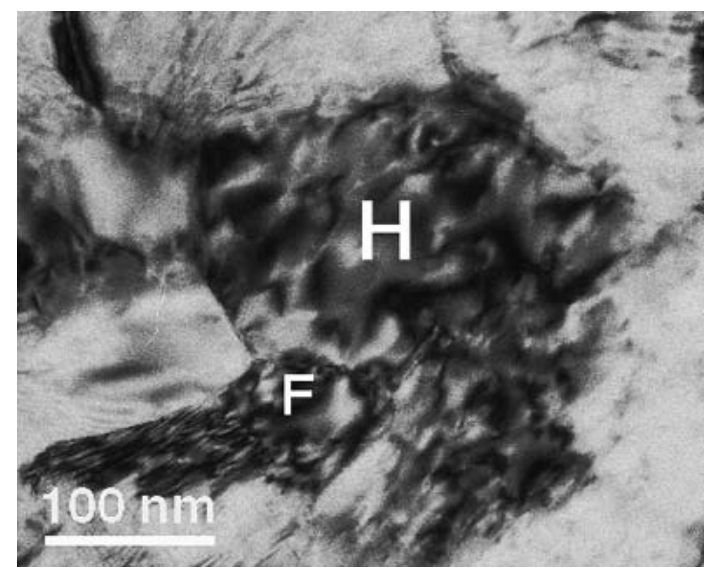

FIG. 3. Grain from area b in Fig. 1(a).

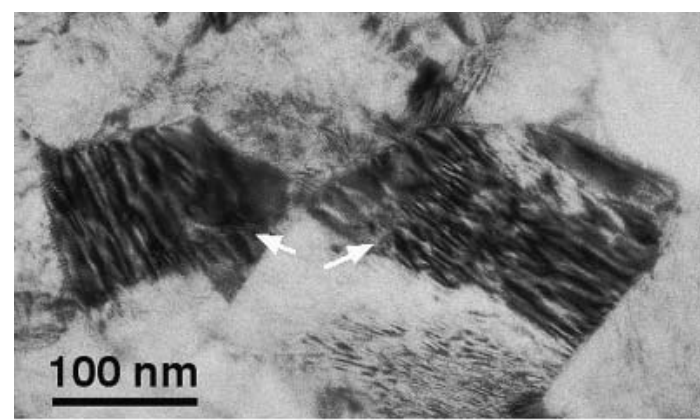

(a)

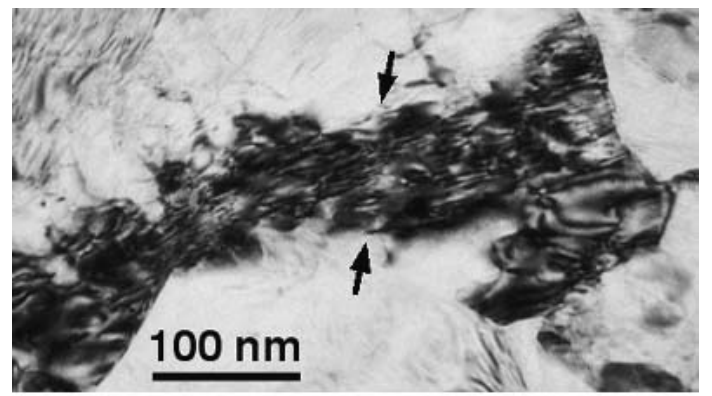

(b)

FIG. 4. BCI is formed when high-density parallel dislocations are oriented to a certain angle to the electron beam.

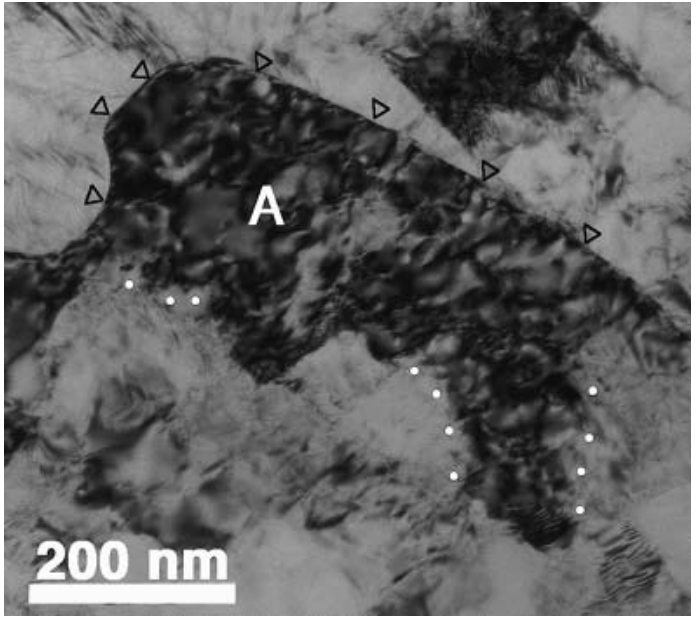

FIG. 5. Both high-angle and low-angle grain boundary segments exist around the same grain.

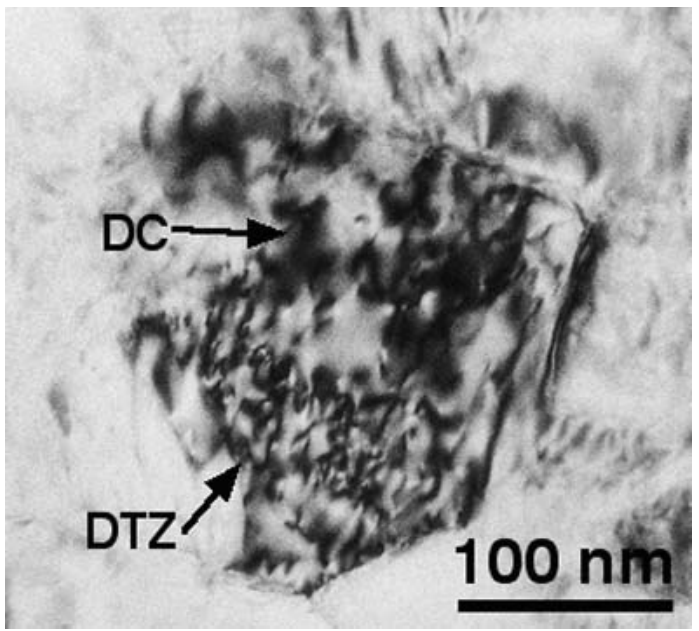

FIG. 6. Grain containing both DTZ and DCs.

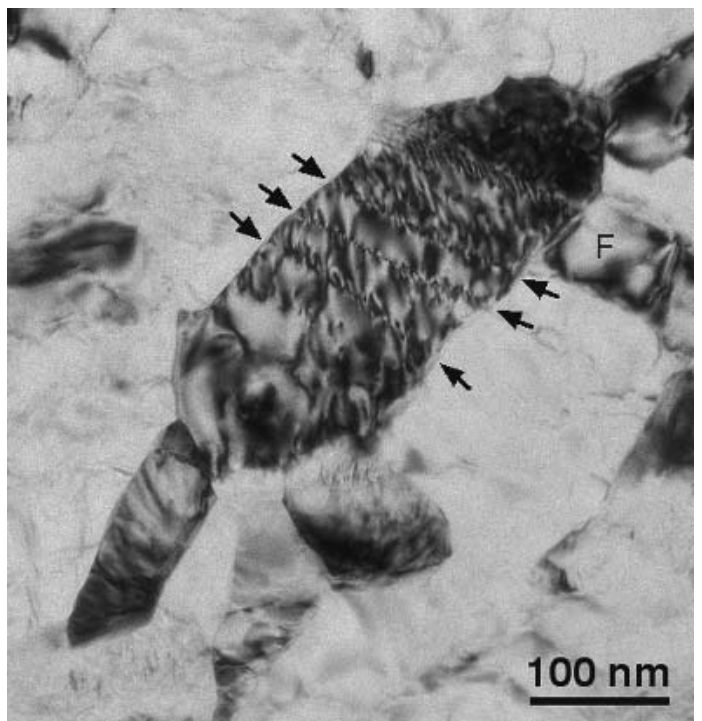

FIG. 7. Grain with dislocations aligning along three lines across the grain. 
dislocation free. The gray contrast inside the grain was generated by dislocations on the grain boundary. The size of the grain is below $100 \mathrm{~nm}$. As discussed later, only small grains and subgrains are dislocation free.

Figure 8 shows a large grain that contains several subgrains, which in turn contain DCs. Such subgrains can also be called cell blocks. ${ }^{16-18}$ Figure 9 shows another large grain that contains only DCs but no subgrains. There are high-density dislocations along a line marked by two white arrows and in an area marked by a white arrow. Obviously, although the grains shown in Figs. 8 and 9 are about the same in size, they contain dramatically different substructures.

Figure 10(a) shows a HRTEM image of a low-angle grain boundary with a misorientation of $6.5^{\circ}$. To check if this grain boundary is in an equilibrium state, the segment of GB inside the white frame was Fourier-filtered to show dislocation arrangements [see Fig. 10(b)], which clearly differ from the structural model in Fig. 10(c). As shown in Fig. 10(c), only two dislocations are needed to accommodate the $6.5^{\circ}$ misorientation across the grain boundary. Such dislocations have been defined as the geometrically necessary dislocations ${ }^{15-18}$ or intrinsic dislocations. ${ }^{30}$ However, there are six dislocations on and

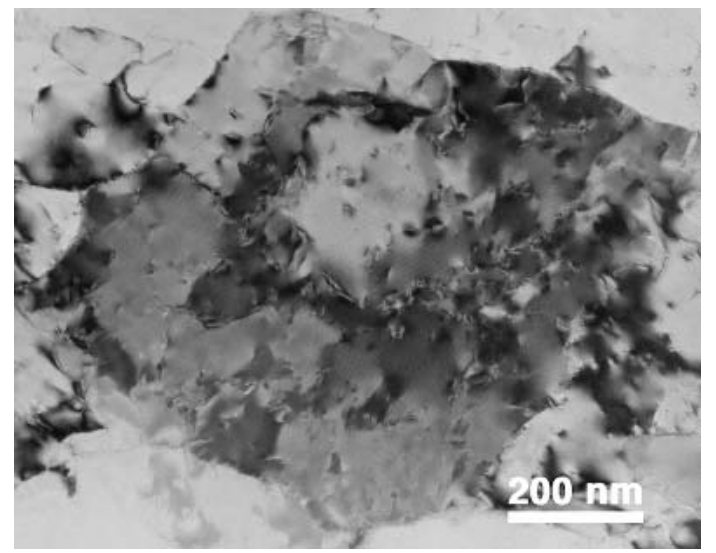

FIG. 8. Large grain containing several subgrains, which in turn contain dislocation cells.

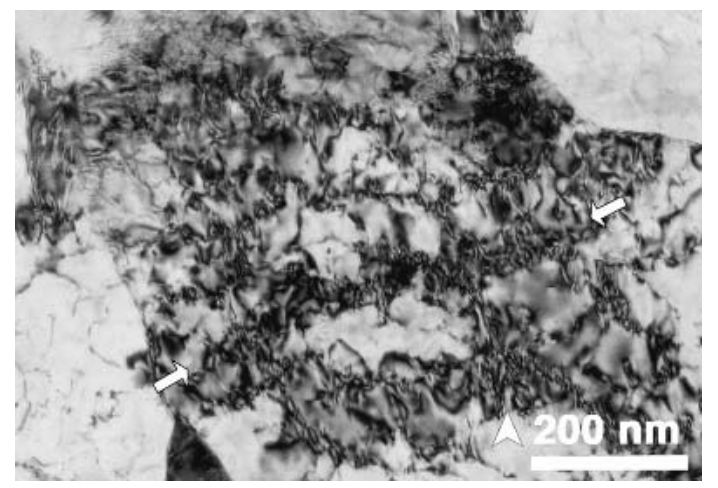

FIG. 9. Large grain containing only dislocation cells but no subgrains. near the grain boundary in Fig. 10(b); four of them are not needed to accommodate the geometric misorientation and can be defined as extrinsic dislocations. These extrinsic dislocations bring extra energy to the grain boundary, making it a non-equilibrium grain boundary, which is a concept that was first suggested in 1986 by Valiev et $a l .{ }^{30}$ and was recently confirmed by Huang et al. ${ }^{15}$

Figure 11 shows the statistical size ranges of different structural features. Grains containing subgrains are usually larger than $320 \mathrm{~nm}$. Grains or subgrains containing DCs are in the size range of $130-600 \mathrm{~nm}$. Grains or subgrains contain dislocations, but no DCs are in the size range of $60-150 \mathrm{~nm}$. Grains or subgrains smaller than $100 \mathrm{~nm}$ may not contain any dislocations except at their boundary. The dislocation cells are in the size range of 30 to $70 \mathrm{~nm}$ and the average cell size is $45 \mathrm{~nm}$.

\section{B. Microstructure from x-ray diffraction peak profile analysis}

Using the $\mathrm{x}$-ray analysis discussed in Sec. II. C, the median and variance of the size distribution of crystallites (or coherently scattering domains) are $m=39 \pm$ $4 \mathrm{~nm}$ and $\sigma=0.14 \pm 0.03$, respectively. The crystallite size distribution is plotted in Fig. 12 using these $m$ and $\sigma$ values. The arithmetic mean crystallite size calculated from Eq. (1) is $\bar{d}=39 \pm 4 \mathrm{~nm}$. The widths of x-ray peaks obtained from the longitudinal section are the same as those from the cross section, suggesting that there is no crystallite shape anisotropy. Since the grains observed by TEM contain several crystallites, the shape anisotropy of some grains in the TEM micrographs is not inconsistent with the isotropic crystallite shape measured by $\mathrm{x}$-ray diffraction. The dislocation density is $\rho=(3.0 \pm 0.6) \times$ $10^{15} \mathrm{~m}^{-2}$, which includes dislocations inside grains and subgrains as well as on dislocation cell boundaries, lowangle grain boundaries, and subgrain boundaries. The experimentally determined $q_{i}$ values are $q_{1}=-1.16 \pm$ 0.09 and $q_{2}=-0.60 \pm 0.08$. Using the method described in Ref. 27, the relative fractions of $\langle a\rangle,\langle c\rangle$, and $\langle c+a\rangle$ dislocations were obtained as:

$$
\begin{aligned}
<a>\text { type, } b & =1 / 3<11 \overline{2} 0>\text {, dislocations: } 66(8) \%, \\
<c>\text { type, } b & =<0001>\text {, dislocations: } 33(5) \%, \\
<c+a>\text { type, } b & =1 / 3<11 \overline{2} 3>\text {, dislocations: } 1 \text { (1) } \% .
\end{aligned}
$$

These values agree very well with previous experimental papers, ${ }^{31-33}$ which reported the abundance of $<a>$ type dislocations besides $<c>$ and $<c+a>$ type dislocations.

\section{DISCUSSION}

\section{A. Comparison of $\mathrm{x}$-ray results with TEM observations}

$\mathrm{X}$-ray is often used to measure the grain size of nanostructured materials ${ }^{34-39}$ because it is simple and readily available. The grain size measured by $\mathrm{x}$-ray has been 
used to interpret mechanical properties of nanostructured materials. ${ }^{36-39}$ For example, Lu et al. ${ }^{38}$ and Nieman et $a l^{39}$ used the grain size measured by $\mathrm{x}$-ray to discuss the Hall-Petch relationship in nanostructured materials. It is well known that the crystallite size in nanostructured materials measured by $\mathrm{x}$-ray is smaller than the grain size observed under TEM. However, there has been no report on what structural features the crystallite size measured by $\mathrm{x}$-ray corresponds to. In this investigation, the arithmetic mean crystallite size from the x-ray analysis data is $39 \pm 4 \mathrm{~nm}$, which is in good agreement with the mean dislocation cell size $(45 \mathrm{~nm})$ as measured from TEM micrographs. Moreover, the crystallite size distribution determined by $\mathrm{x}$-ray peak profile analysis is in good agreement with dislocation cell size distribution obtained by TEM, as shown in Fig. 12. Note that the x-ray experiment analyzed about $10^{9}$ crystallites, whereas the number of cells analyzed by TEM was less than one hundred.

According to our x-ray results, most of the dislocations are of $\langle a\rangle$ type, however, $\langle c\rangle$ type also plays an important role, whereas the presence of $\langle c+a>$ type dislocations is marginal. Extensive TEM investigations on plastically deformed $\mathrm{Ti}$ can be found in the literature. Song and Gray reported strong twinning activity accompanied by the production of $\langle c\rangle$ type dislocations. ${ }^{40}$ Chichili et al. observed mainly $<a>$ type dislocations in addition to $\langle c\rangle$ and $\langle c+a\rangle$ type dislocations. $^{32}$ Twinning has also been reported after $1-2$ ECAP passes. ${ }^{41,42}$ However, after more ECAP passes the twins break up into subcells. ${ }^{7}$ These TEM studies and the observations of Jones and Hutchinson are in good agreement with our results. ${ }^{43}$ We note that Chatterjee and Sen Gupta have also carried out diffraction peak broadening analysis on ball-milled Ti using a less comprehensive procedure and concluded the abundance of $\langle a\rangle$ type dislocations. $^{44}$

\section{B. Nanostructures and their evolution}

As shown in Fig. 11, the Ti processed by warm ECAP plus cold rolling has a mixture of structures, indicating inhomogeneous structural evolution. Such an inhomogeneous structural evolution is typical during plastic deformation, which could be caused by orientation and texture

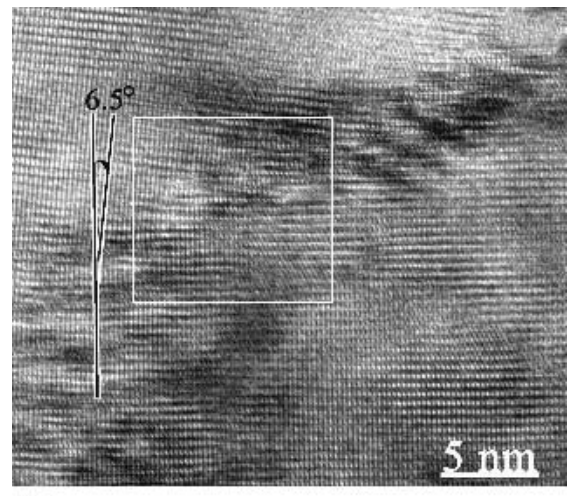

(a)

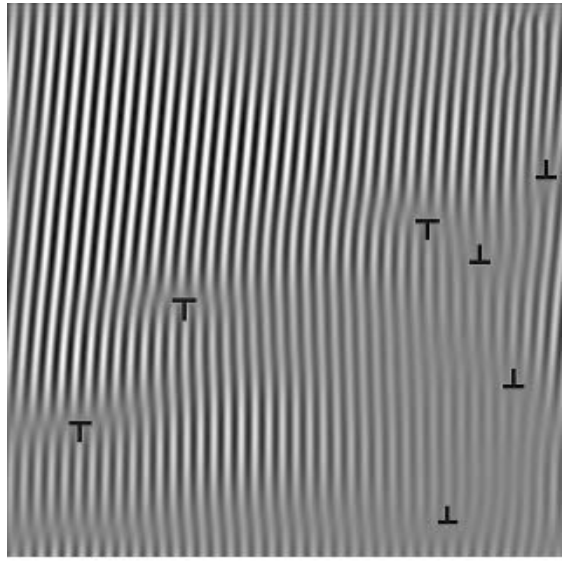

(b)

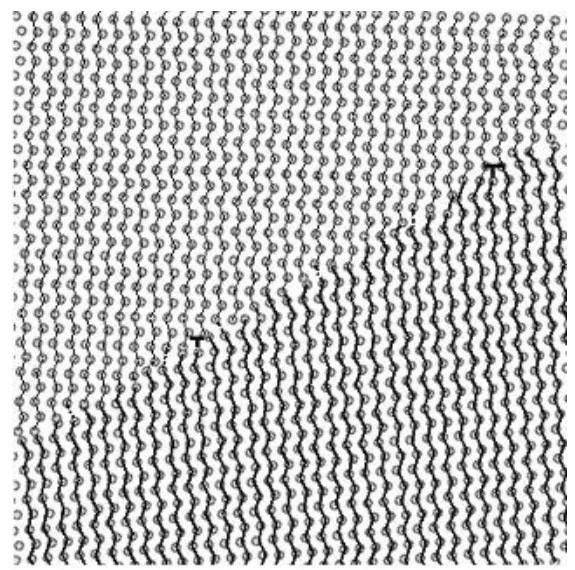

(c)

FIG. 10. (a) HRTEM image of a low-angle grain boundary with a misorientation of $6.5^{\circ}$, (b) Fourier-filtered image from the white frame in (a), showing the dislocation arrangement on the grain boundary, and (c) a structural model of the grain boundary in (b). 
of initial grains ${ }^{45-48}$ as well as the instantaneous orientation history of deformation bands. The final nanostructures observed in this study also shed light on their evolution. The distribution of grain sizes is broad, from less than $100 \mathrm{~nm}$ to over $600 \mathrm{~nm}$. Several types of grains were observed in the nanostructured $\mathrm{Ti}$, depending on their size. Large grains $(>320 \mathrm{~nm})$ may contain subgrains, which may in turn contain dislocation cells. Medium-sized grains (130-600 nm) may have a dislocation cell structure without the intermediate subgrains. Note that there is a large overlap $(320-600 \mathrm{~nm})$ in sizes of grains containing subgrains and grains containing no subgrains. Grains and subgrains smaller than $150 \mathrm{~nm}$ may not contain any dislocation cells. Such grains and subgrains were formed either from previous dislocation cells, or from previous cell blocks that were subdivided so small that they no longer support cell structures. It is reasonable to assume that relatively larger grains containing no dislocation cells (closer to $150 \mathrm{~nm}$ in size)

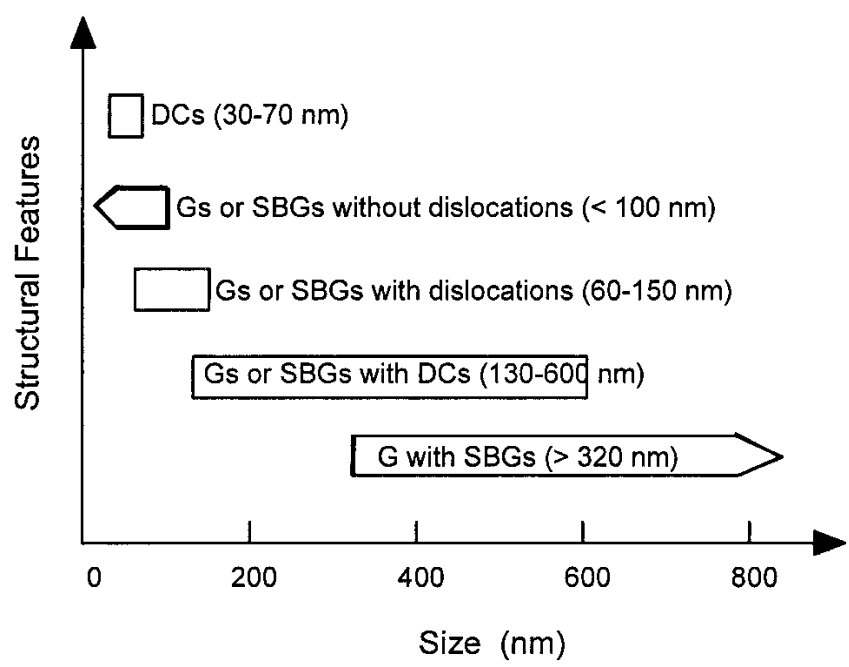

FIG. 11. Hierarchy and size ranges of different structural features.

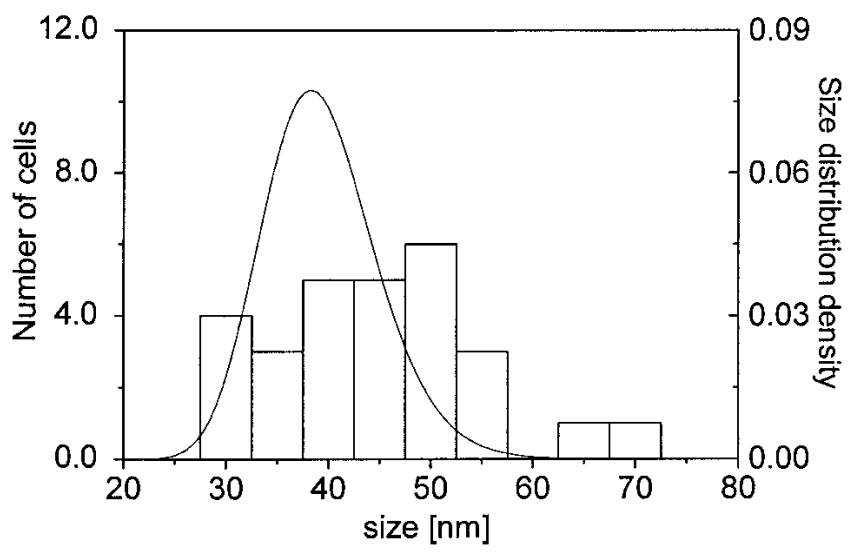

FIG. 12. Comparison of the histogram of dislocation-cell size distribution determined by TEM with the crystallite size density distribution (solid line, right coordinate) determined by x-ray analysis. were more likely evolved from cell blocks. For grains that are very small (less than $100 \mathrm{~nm}$, typically around $75 \mathrm{~nm}$ ), dislocations may no longer exist inside the grains. All dislocations were absorbed on the grain boundaries. Considering that the dislocation cell sizes are in the range of 30 to $70 \mathrm{~nm}$, the smaller grains containing no dislocations were likely evolved from dislocation cells.

Unlike fcc metals with medium-to-high stacking fault energies, ${ }^{16}$ twinning plays an important role in the deformation of hexagonal close-packed (hcp) titanium. ${ }^{49,50}$ The twining undoubtedly played a major role in grain refinement, at least in the early stage of deformation when the accumulative strain is low. It is interesting that no twins were observed in the subgrain level, although some grains with straight boundaries and elongated shape [see Fig. 1(b)] could have been produced by twinning. The existence of extensive dislocation cells (See Figs. 2,3,5,6,8,9,12) and the extremely high dislocation densities measured by $\mathrm{x}$-ray analysis suggest that dislocation slip was the primary deformation mechanism in the later stage of SPD. The co-existence of DTZ and dislocation cells (Fig. 6) suggest that dislocation cells were formed by the rearrangement of dislocations, which is a recovery process that reduces the dislocation density.

The BCI shown in Fig. 4 has been also observed in nanostructured $\mathrm{Cu}$ produced by HPT for five revolutions under a pressure of $5 \mathrm{GPa} .{ }^{51}$ However, no such BCI was observed in $\mathrm{Cu}$ samples processed by smaller number of revolutions. Although the ECAP technique has been extensively used to process various metals and alloys, no $\mathrm{BCI}$ has been reported in any nanostructured materials processed by ECAP. We believe that only extreme strain conditions can produce BCI in nanostructured materials. Such extreme strain conditions can generate very high dislocation density and make the dislocations align in a parallel and closely spaced manner (see Fig. 7). The strain fields of the closely spaced, parallel dislocations interact with each other and show the BCI when oriented in a certain angle with the electron beam. The nanostructured $\mathrm{Ti}$ in this study was first processed by ECAP for eight passes at $400-450{ }^{\circ} \mathrm{C}$ and then cold rolled to the $73 \%$ strain. The BCIs were formed during the cold rolling since they were not observed after the ECAP. ${ }^{7}$

\section{Correlations between nanostructures and mechanical behavior}

The nanostructures revealed in this study also shed light on the mechanical behavior observed for the UFGTi processed through warm ECAP + cold rolling. The quasistatic stress-strain curves obtained in tension and in compression at room temperature have been reported in Ref. 9. The yield strength and ultimate strength of the nanostructured Ti are $\sim 900 \mathrm{MPa}$ and $\sim 1000 \mathrm{MPa}$, respectively. There was no strain hardening in the compressive 
stress-strain curve except at the beginning when the strain is less than 0.05 . Early necking was observed in the tensile stress-strain curve. The strain-rate sensitivity was found to be lower than that of coarse-grained Ti. Interestingly, a good ductility (elongation to failure) of 9\% was observed despite the lack of strain hardening and low strain-rate sensitivity, much higher than that for typical cold-rolled Ti.

The lack of strain hardening ${ }^{9}$ can be attributed to the small dislocation cell and grain size, as recently suggested by Park and Shin, ${ }^{52}$ as well as high defect density. In the as-processed material, the defect storage is likely to be already close to the saturation limit. The majority of the additional dislocations generated during straining do not accumulate, as they annihilate or disappear into sinks that are abundant in a material with such ultrafine grains and cell structures. For example, the cell boundaries can act as both a dislocation source and sink, with dislocations bowing out of one segment of a cell boundary and disappearing into another segment across the cell. In other words, the defect generation and recovery are near a dynamic balance with no significant change in defect density. The stress-strain curve thus stays flat with no obvious strain hardening for at least a range of plastic strains.

The lack of strain hardening and low strain-rate sensitivity in this strong material promote the plastic instability (i.e., necking in tension). However, the total elongation to failure is of the order of $10 \%$, higher than that for typical cold-rolled Ti. This is due to significant post-necking plastic strain achieved in localized deformation zone before fracture. The fracture surface exhibits features indicating ductile fracture through submicrometer dimple nucleation and coalescence (see Fig. 13). It is likely that the toughness observed benefited from the high degree of microstructural refinement achieved in our Ti. The finer grain size in nanostructured Ti led to the formation of very fine dimples with an average diameter of $\sim 600 \mathrm{~nm}$ [Fig. 13(a)], instead of large dimples $(5-20 \mu \mathrm{m})$ in coarse-grained Ti [Fig. 13(b)]. Finer grains have higher resistance to crack nucleation and propagation. ${ }^{53}$ These fine dimples caused smaller local stress concentration in unfractured ligaments near the dimple edge than large dimples in coarse-grained $\mathrm{Ti}$, which makes the nanostructured $\mathrm{Ti}$ more resistant to fracture.

The well-known Hall-Petch model ${ }^{54,55}$ is often used to predict the strength variation with grain size: $\sigma_{\mathrm{y}}=\sigma_{0}+$ $\mathrm{kd}^{-1 / 2}$, where $\sigma_{\mathrm{y}}$ is the yield strength, $\sigma_{0}$ and $\mathrm{k}$ are constants, whose value for Ti can be found from literature ${ }^{56}$ as $\sigma_{0}=134.2 \mathrm{MPa}$ and $\mathrm{k}=0.671 \mathrm{MPam}^{-1 / 2}$. Using these values and the measured grain size of $265 \mathrm{~nm}$, the yield strength is calculated to be $1437 \mathrm{MPa}$, which is about $60 \%$ higher than the experimental yield strength. Therefore, the Hall-Petch relationship known for coarsegrained $\mathrm{Ti}$ cannot be applied to the nanostructured $\mathrm{Ti}$ using the TEM measured grain size. Also note that the "crystallite" size obtained from x-ray analysis cannot be used in the Hall-Petch equation to calculate the strength, which overestimates the strength of nanostructured Ti by 2.75 times.

Two different models have been proposed to explain the origin of the Hall-Petch relationship. The first model is dislocation pileup at grain boundaries. ${ }^{54,55,57}$ However, such mechanism may not operate in nanostructured Ti because the small grains limit the dislocation pileup. Muñoz-Morris et al. observed that an utrafine-grained $\mathrm{Al}-\mathrm{Mg}$ alloy had lower yield strengths than predicted by the Hall-Petch relationship. ${ }^{58}$ They attributed the lower yield strength to low-angle grain boundaries in most grains, which have lower resistance to dislocation pileup. They argued that if the average distance between highangle grain boundaries is used in the Hall-Petch equation, the yield strength would be much closer to predicted values. For our experimental results on CP-Ti, using $\sigma_{0}$, $\mathrm{k}$, and observed yield strength of $900 \mathrm{MPa}$, the grain size can be calculated as $636 \mathrm{~nm}$, which is much larger than the observed average grain size $(265 \mathrm{~nm})$ but near the upper

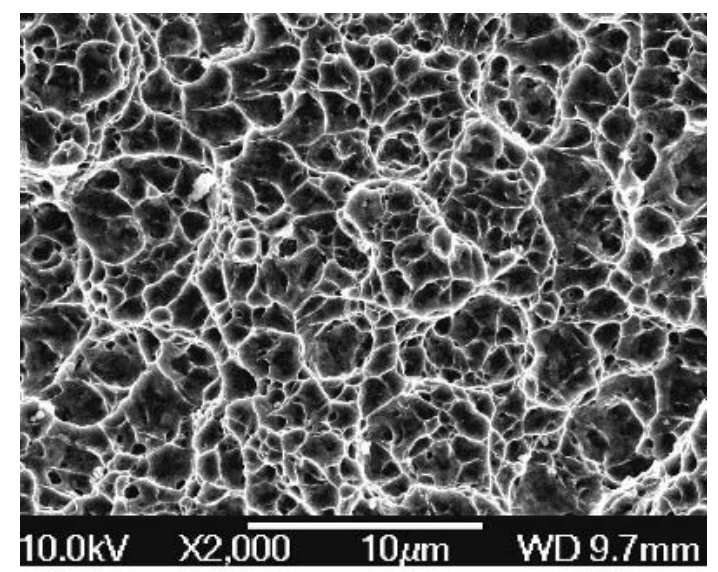

(a)

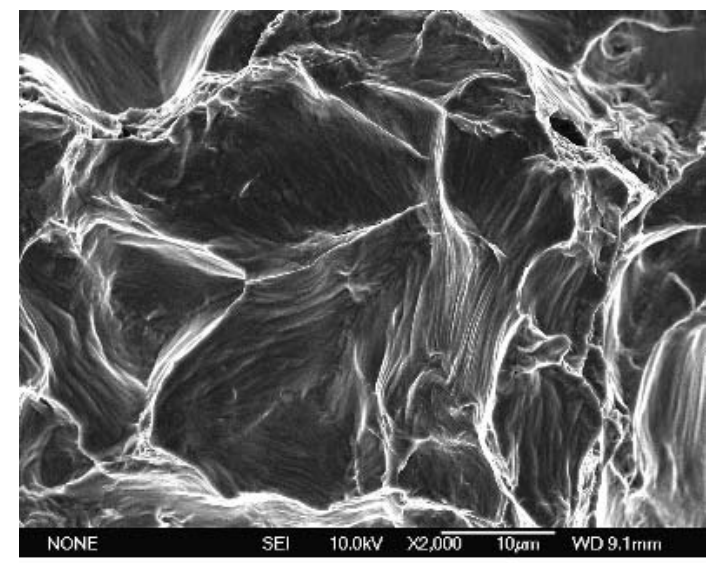

(b)

FIG. 13. SEM images of fracture surfaces showing that (a) nanostructured $\mathrm{Ti}$ resulted in very fine dimples $(\sim 600 \mathrm{~nm})$ and (b) coarsegrained Ti resulted in large dimples $(5-20 \mu \mathrm{m})$. 
limit of observed grain size range (Fig. 11). Interestingly, the calculated grain size $(636 \mathrm{~nm})$ agrees reasonably well with the dimple size on the fractured surface [Fig. 13(a)]. However, such an agreement could be coincidental. More studies are required to determine if there is a direct relationship between the yield strength and the dimple size.

The second model is based on the observation of nonuniform dislocation distribution between regions near grain boundary and in the grain interior. ${ }^{59}$ The model produced a modified Hall-Petch relationship: $\sigma_{\mathrm{y}}=\sigma_{0}+$ $8 \mathrm{k}\left(\sigma_{\mathrm{GB}}-\sigma_{\mathrm{I}}\right) \mathrm{d}^{-1 / 2}-16 \mathrm{k}^{2}\left(\sigma_{\mathrm{GB}}-\sigma_{\mathrm{I}}\right) d^{-1}$, where $\sigma_{\mathrm{GB}}$ and $\sigma_{\mathrm{I}}$ are flow stresses near the grain boundary and in the grain interior, respectively. Such a model does predict that for very small grains the measured yield strength becomes lower than predicted by the conventional HallPetch relationship. This model agrees better with our experimental results. However, the applicability of this model to nanostructured materials needs to be examined further.

Another possible estimation for the strength of nanostructured $\mathrm{Ti}$ can be based on the dislocation density measured by the x-ray peak profile analysis. According to the Taylor equation, the yield strength can be related to the dislocation density as $\sigma_{\mathrm{y}}=\alpha G b \sqrt{\rho}$, where $\alpha$ is a constant, $G$ is the shear modulus, $b$ is the absolute value of the average Burgers vector, and $\rho$ is the average dislocation density. In the case of nanostructured titanium $G=45.6 \mathrm{GPa}, \sigma_{\mathrm{y}}=900 \mathrm{MPa}, b=0.347 \mathrm{~nm}$ (the average Burgers vector value calculated from the relative fractions of the three different types of dislocations determined by $\mathrm{x}$-ray analysis), and $\rho=3 \times 10^{15} \mathrm{~m}^{-2}$. With these values, $\alpha$ is obtained to be 1.04 , which is close to 1 , the value usually obtained for cubic materials. ${ }^{60,61}$ The $\alpha$ value for hcp materials has not been reported. In addition, the dislocation distribution could also affect the yield strength. Nevertheless, the above analysis shows that the high dislocation density was most likely a dominant factor in determining the strength of nanostructured $\mathrm{Ti}$ in this study.

\section{CONCLUSIONS}

The structural evolution of Ti during warm ECAP plus cold rolling is inhomogeneous at the grain/subgrain level, leading to a hierarchy of nanostructures. The grain sizes range from less than $100 \mathrm{~nm}$ to over $600 \mathrm{~nm}$. Large grains $(>320 \mathrm{~nm}$ ) may contain subgrains, which may in turn contain dislocation cells, while medium-sized grains (130-600 nm) may have a cell structure without intermediate subgrains. Grains and subgrains smaller than $150 \mathrm{~nm}$ may not contain any dislocation cells. Grains smaller than $100 \mathrm{~nm}$ could be dislocation free in their interior. Nonequilibrium grain boundaries containing extrinsic dislocations were observed.

The arithmetic mean crystallite size determined by $\mathrm{x}$ ray analysis is $\sim 39 \pm 4 \mathrm{~nm}$, which agrees well with the average dislocation cell size $(45 \mathrm{~nm})$ determined from
TEM observation. In addition, the crystallite size distribution determined by x-ray analysis also agrees well the dislocation cell size distribution determined by TEM. The dislocation density calculated from the x-ray diffraction data is $\rho=(3.0 \pm 0.6) \times 10^{15} \mathrm{~m}^{-2}$. The $\mathrm{x}$-ray analysis determined the Burgers vector composition in the dislocation structure as $66 \%<a>$ type, $33 \%<c>$ type, and $1 \%<c+a>$ type.

The conventional Hall-Petch equation cannot be applied to nanostructured $\mathrm{Ti}$, while a modified Hall-Petch equation agrees better with our experimental results but needs to be further examined. The lack of strain hardening in the nanostructured $\mathrm{Ti}$ is caused by the small sizes of grains, subgrains, and dislocation cells. The small grain size led to smaller dimples during the necking process in tensile tests, which might have contributed to the enhanced fracture resistance and ductility.

\section{ACKNOWLEDGMENTS}

This work was supported by the IPP program of the United States Department of Energy and Hungarian Scientific Research Fund, OTKA, Grant Nos. T031786, T034666, and T029701. J.G. is grateful for the financial support of Magyary Zoltán postdoctoral program of Foundation for Hungarian Higher Education and Research (AMFK). Y.M.W. and EM acknowledge the partial support by the United States National Science Foundation, Grant No. CMS-9877006.

\section{REFERENCES}

1. P.G. Sanders, J.A. Eastman, and J.R. Weertman, Acta Mater. 45, 4019 (1997).

2. Z. Horita, M. Furukawa, M. Nemoto, A.J. Barnes, and T.G. Langdon, Acta. Mater. 48, 3633 (2000).

3. X. McFadden, R.S. Mishra, R.Z. Valiev, A.P. Zhilyaev, and A.K. Mukherjee, Nature 398, 684 (1999).

4. R.Z. Valiev, R.K. Islamgaliev, and I.V. Alexandrov, Prog. Mater. Sci. 45, 103 (2000).

5. S.R. Agnew, B.R. Elliott, C.J. Yongdahl, K.J. Hemker, and J.R. Weertman, Mater. Sci. Eng. A 285, 391 (2000).

6. Z. Horita, T. Fujinami, M. Nemoto, and T.G. Langdon, Metall. Mater. Trans. 31A, 691 (2000)

7. V.V. Stolyarov, Y.T. Zhu, I.V. Alexandrov, T.C. Lowe, and R.Z. Valiev, Mater. Sci. Eng. A 299, 59 (2000).

8. V.V. Stolyarov, Y.T. Zhu, T.C. Lowe, and R.Z. Valiev, Mater. Sci. Eng. A 303, 82 (2001).

9. D. Jia, Y.M. Wang, K.T. Ramesh, E. Ma, Y.T. Zhu, and R.Z. Valiev, Appl. Phys. Lett. 79, 611 (2001).

10. R.Z. Valiev, I.V. Alexandrov, Y.T. Zhu, and T.C. Lowe, J. Mater. Res. 17, 5 (2002).

11. Y.T. Zhu, H. Jiang, J.Y. Huang, and T.C. Lowe, Metall. Mater. Trans. 32A, 1559 (2001).

12. E.A. Brandes and G.B. Brook, Smithells Metals Reference Book, 7th ed. (Butterworth-Heinemann Ltd., Oxford, U.K., 1992), Chapter 22.

13. E.R. Parker, Materials Data Book for Engineers and Scientists (McGraw-Hill Book Co., New York, 1967). 
14. S.S. Hecker and M.G. Stout, Deformation, Processing and Structure, edited by G. Krauss (ASM, Materials Park, OH, 1984), pp. 1-15.

15. J.Y. Huang, Y.T. Zhu, H. Jiang, and T.C. Lowe, Acta Mater. 49, 1497 (2001).

16. B. Bay, N. Hansen, D.A. Hughes, and D. Kuhlmann-Wilsdorf, Acta Mater. 40, 205 (1992).

17. N. Hansen and X. Huang, Acta Mater. 46, 1827 (1998).

18. Q. Liu, D. Juul Jensen, and N. Hansen, Acta Mater. 46, 5819 (1998).

19. Z. Horita, D.J. Smith, M. Nemoto, R.Z. Valiev, and T.G. Langdon, J. Mater. Res. 13, 446 (1998).

20. K. Oh-ishi, Z. Horita, D.J. Smith, and T.G. Langdon, J. Mater. Res. 16, 583 (2001).

21. R.Z. Valiev, C. Song, S.X. McFadden, A.K. Mukherjee, and R.S. Mishra, Philos. Mag. A 81, 25 (2001).

22. V.V. Stolyarov, Y.T. Zhu, I.V. Alexandrov, T.C. Lowe, and R.Z. Valiev, J. Nanosci. Nanotechnol. 237, (2001).

23. T. Ungár, J. Gubicza, G. Ribárik, and A. Borbély, J. Appl. Crystallogr. 34, 298 (2001).

24. G. Ribárik, T. Ungár, and J. Gubicza, J. Appl. Crystallogr. 34, 669 (2001).

25. M. Wilkens, Phys. Status Solidi A 2, 359 (1970).

26. M. Wilkens, in Fundamental Aspects of Dislocation Theory, edited by J.A. Simmons, R. de Wit, and R. Bullough (U.S. Nat. Bur. Stand. Spec. Publ. 317, Washington, DC, 1970), Vol. II, p. 1195.

27. C.I. Dragomir and T. Ungár, J. Appl. Crystalogr. 35, 556 (2002).

28. W.C. Hinds, Aerosol Technology: Properties, Behavior and Measurement of Airbone Particles (Wiley, New York, 1982).

29. J.I. Langford, D. Louër, and P. Scardi, J. Appl. Crystallogr. 33, 964 (2000).

30. R.Z. Valiev, V. Yu Gertsman, and O.A. Kaibyshev, Phys. Status Solidi A 97, 11 (1986).

31. S. Farenc, D. Caillard, and A. Couret, Acta Metall. Mater. 41, 2701 (1993).

32. D.R. Chichili, R.K.T. Ramesh, and K.J. Hemker, Acta Mater. 46, 1025 (1998).

33. A. Girschick, D.G. Pettifor, and V. Vitek, Philos. Mag. A 77, 999 (1998).

34. I.V. Alexandrov, K. Zhang, A.R. Kilametov, K. Lu, and R.Z. Valiev, Mater. Sci. Eng. A 234-236, 331 (2001).

35. K. Isonishi and K. Okazaki, J. Mater. Sci. 28, 3829 (1993).

36. H.J. Fecht, E. Hellstern, Z. Fu, and W.L. Johnson, Metall. Trans. 21A, 2333 (1990).
37. L. He and E. Ma, NanoStruct. Mater. 7, 327 (1996).

38. K. Lu, H.Y. Zhang, Y. Zhong, and H.J. Fecht, J. Mater. Res. 12, 923 (1997).

39. G.W. Nieman, J.R. Weertman, and R.W. Siegel, J. Mater. Res. 6, 1012 (1991).

40. S.G. Song and G.T. Gray III, Acta Metall. Mater. 43, 2339 (1995).

41. I. Kim, J. Kim, D.H. Shin, X.Z. Liao, and Y.T. Zhu, Scripta Mater. 48, 813 (2003).

42. D.H. Shin, I. Kim, J. Kim, Y.S. Kim, and S.L. Semiatin, Acta Mater. 51, 983 (2002).

43. I.P. Jones and W.B. Hutchinson, Acta Metall. 29, 951 (1981).

44. P. Chatterjee and S.P. Sen Gupta, Philos. Mag. A 81, 49 (2001).

45. H. Chandra, J.D. Embury, and U.F. Kocks, Scripta Metall. 16, 493 (1982).

46. N. Hansen and X. Huang, Acta Mater. 46, 1827 (1998).

47. Q. Liu, C. Maurice, J. Driver, and N. Hansen, Metall. Mater. Trans. 29A, 2333 (1999).

48. P.B. Prangnell and J.R. Bowen, in Ultrafine Grained Materials II, edited by Y.T. Zhu, T.G. Langdon, R.S. Mishra, S.L. Semiatin, M.J. Saran, and T.C. Lowe (TMS, Warrendale, PA, 2002), pp. 89-98.

49. D.H. Shin, I. Kim, J. Kim, and Y.T. Zhu, Mater. Sci, Eng. A 334, 239 (2002).

50. A.A. Salem, S.R. Kalidini, and R.D. Doherty, Scripta Mater. 46, 419 (2002).

51. H. Jiang, Y.T. Zhu, D.P. Butt, I.V. Alexandrov, and T.C. Lowe, Mater. Sci. Eng. A 290, 128 (2000).

52. K.T. Park and D.H. Shin, Metall. Mater. Trans. A 33, 705 (2002).

53. R.W. Hertzberg, Deformation and Fracture Mechanics of Engineering Materials, 3rd ed. (John Wiley and Sons, New York, 1989), p. 392.

54. E.O. Hall, Proc. Phys. Soc. Series B 64, 747 (1951).

55. N.J. Petch, J. Iron and Steel Inst. 174, 25 (1953).

56. A.A. Salem, S.R. Kalidindi, and R.D. Doherty, Scripta Mater. 46, 419 (2002).

57. A.H. Cottrell, Transactions of the Metallurgical Society of AIME 212, 192 (1963).

58. M.A. Meyers and E. Ashworth, Philos. Mag. 35, 1161 (1977).

59. M.A. Muñoz-Morris, C.G. Oca, and D.G. Morris, Scripta Mater. 48, 213 (2003).

60. U.F. Kocks and H. Mecking, Prog. Mater. Sci. 48, 171 (2003).

61. R.W.K. Honeycombe, The Plastic Deformation of Metals (Edward Arnold, London, U.K., 1984), p. 129. 